\title{
Improving sex and gender identity equity and inclusion at conservation and ecology conferences
}

\author{
Ayesha I. T. Tulloch (1)
}

\begin{abstract}
Conferences are important for professional learning and for building academics' reputations and networks. All members of the scientific community should feel supported and free to contribute their best at such events. I evaluated the actions and policies of conferences held by international academic societies for ecology and conservation since 2009, to assess whether conferences support participation across sexual orientations and gender identities. Although half of the $\mathbf{3 0}$ conferences had codes of conduct promoting equity, diversity and inclusion, the quantity and quality of initiatives to support such principles varied between societies and years. Conferences with codes were significantly more likely to implement structural initiatives to minimize discrimination or harassment, such as procedures for reporting misconduct and submission guidelines to promote speaker diversity, as well as initiatives to support parents. Initiatives minimizing barriers to attendance were rare; $47 \%$ of conferences were held in locations that discriminate against certain identities and $<10 \%$ promoted event safety and accessibility to potential attendees. Piecemeal actions and inadequate conference evaluation have resulted in no significant growth in gender equity or diversity initiatives. I propose a six-step timeline that improves conference inclusion by embedding diversity and equity into planning, financing, marketing, scientific and social scheduling, evaluation and reporting.
\end{abstract}

ncreasing social and cultural acceptance of diverse identities and acknowledgement of historical and current inequalities and discrimination has led to growing support for principles of equity, diversity and inclusion in academia ${ }^{1-6}$. Equity is an approach to ensure that everyone can access the same opportunities, regardless of their personal and cultural characteristics, whilst inclusion ensures equality of opportunity by removing barriers or obstacles that might previously have prevented access ${ }^{7}$. More and more academic workplaces have implemented structural or regulatory fixes focused on increasing diversity and widening social acceptance $e^{7,8}$. Workplace gender equity, specifically women's rights, has been the focus of such fixes for more than 50 years, from policies on equal employment opportunities and pay for women ${ }^{9}$, to certification programmes such as the Athena Swan Charter for Women in Science ${ }^{7,10-12}$. Regulatory fixes have had many positive outcomes. Workplaces are more diverse-representation of women in academic and leadership roles ${ }^{11,13,14}$, and proportional representation of female $\mathrm{PhD}$ graduates, has increased in all academic disciplines ${ }^{15}$. Workplaces are also more equitable for women-female scientists in Athena SWAN certified institutions experience greater career satisfaction and fairness in workload allocation and increased opportunities.

Despite growth in workplace gender equity policies, discrimination, harassment and inequalities based on gender identity and sexual orientation are still widespread ${ }^{16-22}$ (see Extended Data Fig. 1 for glossary). Estimates suggest that the representation of LGBTQIA+ (the lesbian, gay, bisexual, pansexual, transgender, genderqueer, queer, intersexed, agender, asexual and ally community) people in science, technology, engineering and mathematics (STEM) is $17-21 \%$ lower than would be expected from national estimates and $40 \%$ of LGBTQIA+ scientists were not out to their colleagues in a 2013 survey $^{23-25}$. Differential treatment and discrimination occur due to structural and socio-economic barriers (for example, wage inequalities $)^{20,21,26,27}$, implicit and explicit biases and exclusion from opportunities ${ }^{28,29}$, incivility (both perceived and real $)^{30}$, persecution ${ }^{31-33}$, and inadequate leadership ${ }^{34-36}$. In addition to affecting science outcomes ${ }^{37}$, discrimination leads to health issues and poses risks to the performance and legitimacy of institutions ${ }^{32}$. Although research on policies specifically supporting LGBTQIA+ and inclusion is scarce, studies indicate that implementing LGBTQIA+-supportive policies leads to lower levels of discrimination and higher worker well-being in the workplace ${ }^{17,38}$.

Conferences are vital components of the academic working environment as they enable researchers to communicate new discoveries and network with colleagues, funding agencies and practitioners ${ }^{39,40}$. Unfortunately, conferences can foster unequal power dynamics that privilege certain attendees over others. For example, even in female-rich disciplines there are more men in leadership roles $^{41}$, more male speakers at conferences ${ }^{42-44}$, and men speak more often than women ${ }^{45,46}$. Codes of conduct are regulatory fixes that outline expected ethical behaviour to ensure safe, inclusive and equitable conference environments, and discourage discrimination and harassment ${ }^{47-49}$. Professional and academic societies around the world have voluntarily begun to implement codes of conduct and additional initiatives to support diversity, equity and inclu$\operatorname{sion}^{48}$ (Extended Data Fig. 2). However, the efficacy of such policies at conferences remains largely unexplored ${ }^{44}$. Evaluation of policy effectiveness is critical to ensuring that policies remain relevant and succeed at reducing inequalities and discrimination.

The principles of diversity, equity and inclusion are enmeshed in the disciplines of conservation and ecology as decisions about the environment also impact human well-being and social justice. Understanding and addressing the diversity of human values and needs is critical to effective conservation outcomes ${ }^{50-52}$. For these reasons, we might expect to see strong support for equity, diversity and inclusion in ecology and conservation events. To evaluate how ecology and conservation conferences support these principles, I reviewed the actions and policies of ten international 
Conference code of ethical conduct

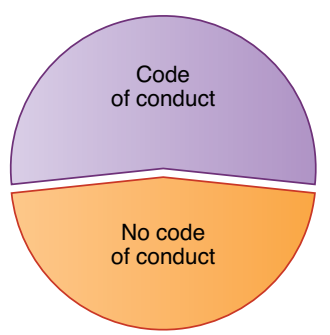

1. Minimize discrimination, implicit bias and harassment

Equity/diversity committee
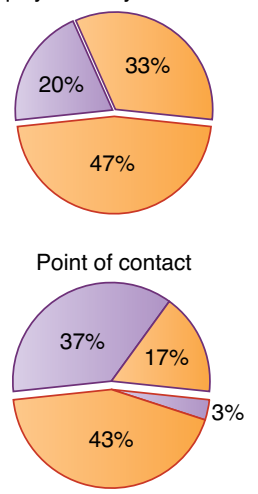

Submission guidelines for abstracts and sessions

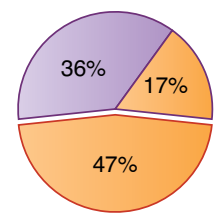

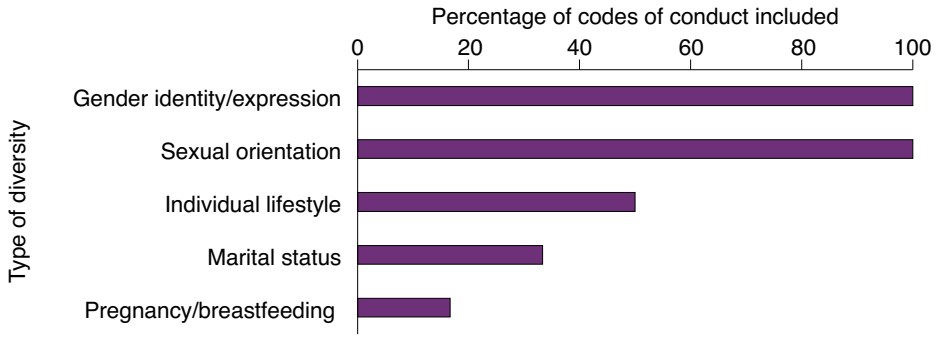

Initiatives to improve equity and inclusion

2. Minimize barriers to attendance

Grants or discounts

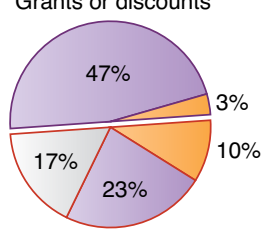

Inclusive location

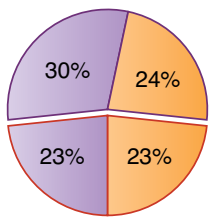

No data

Included initiative at event

Did not include initiative at event
Diversity social event

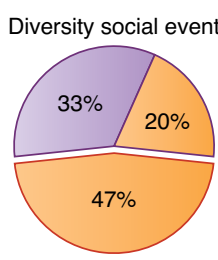

3. Maximize inclusion and education during conference

Diversity talks, sessions and/or workshops

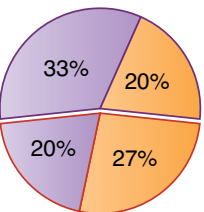

Code of conduct

No code of conduct

Fig. 1 Summary of the equity and diversity initiatives implemented by ten conferences in ecology and conservation. The results indicate the percentage of conference events that did (purple shading) or did not (orange shading) implement an initiative relative to whether conferences did (purple outline) or did not (orange outline) have codes of conduct.

conferences held by nine academic societies for ecology and conservation. Data were collated for the past three events that had been held by each conference targeting an international audience: the biannual International Congress for Conservation Biology (ICCB), International Marine Conservation Congress (IMCC), European Ecological Federation (EEF) Conference and the Society for Ecological Restoration (SER) World Conference on Ecological Restoration, the annual conferences of the Ecological Society of America (ESA), Ecological Society of Australia (ESAus), British Ecological Society (BES) and Association for Tropical Biology and Conservation (ATBC), the conference of the International Association for Ecology (INTECOL), and the International Union for Conservation of Nature (IUCN) World Conservation Congress (WCC) held once every four years (see Supplementary Methods for review methods). I focused on the initiatives instigated by academic societies to support equity and diversity in sex, gender identity and sexual orientation ${ }^{7,23,30,43,44,47,48,53-57}$, and associated diversity types and lifestyle choices-marital status, family or carer responsibilities, pregnancy and breastfeeding and physical appearance (Fig. 1, Table 1). I grouped initiatives according to three broad objectives of improving equity: (1) minimizing discrimination, implicit bias and harassment; (2) Minimizing barriers to attendance; or (3) maximizing inclusion and education (Fig. 1), and compared the initiatives implemented by conferences with codes of conduct to those that did not have a code of conduct. I also explored whether the occurrence of such initiatives at conferences has increased over time. Codes of conduct were not correlated with the implementation of $50 \%$ of equity, diversity and inclusion initiatives at recent conservation and ecology conferences (Table 1), suggesting that such codes are necessary but insufficient on their own for achieving equity and inclusion. I draw from the range of positive initiatives to provide a six-step timeline to improve diversity and inclusion related to gender and sexual orientation at future conferences. The framework can be adapted to support other diversity types such as age, disabilities, race and religion.

\section{Minimizing discrimination, implicit bias and harassment}

A strong diversity policy and code of conduct advertises to potential attendees that the conference supports principles of equity, diversity and inclusion, especially if the code is accompanied by expectations of attendee behaviour and consequences if such rules were bro$\mathrm{ken}^{48}$. By 2020, 6 of the 10 conferences (and 16 of all 30 events) had 


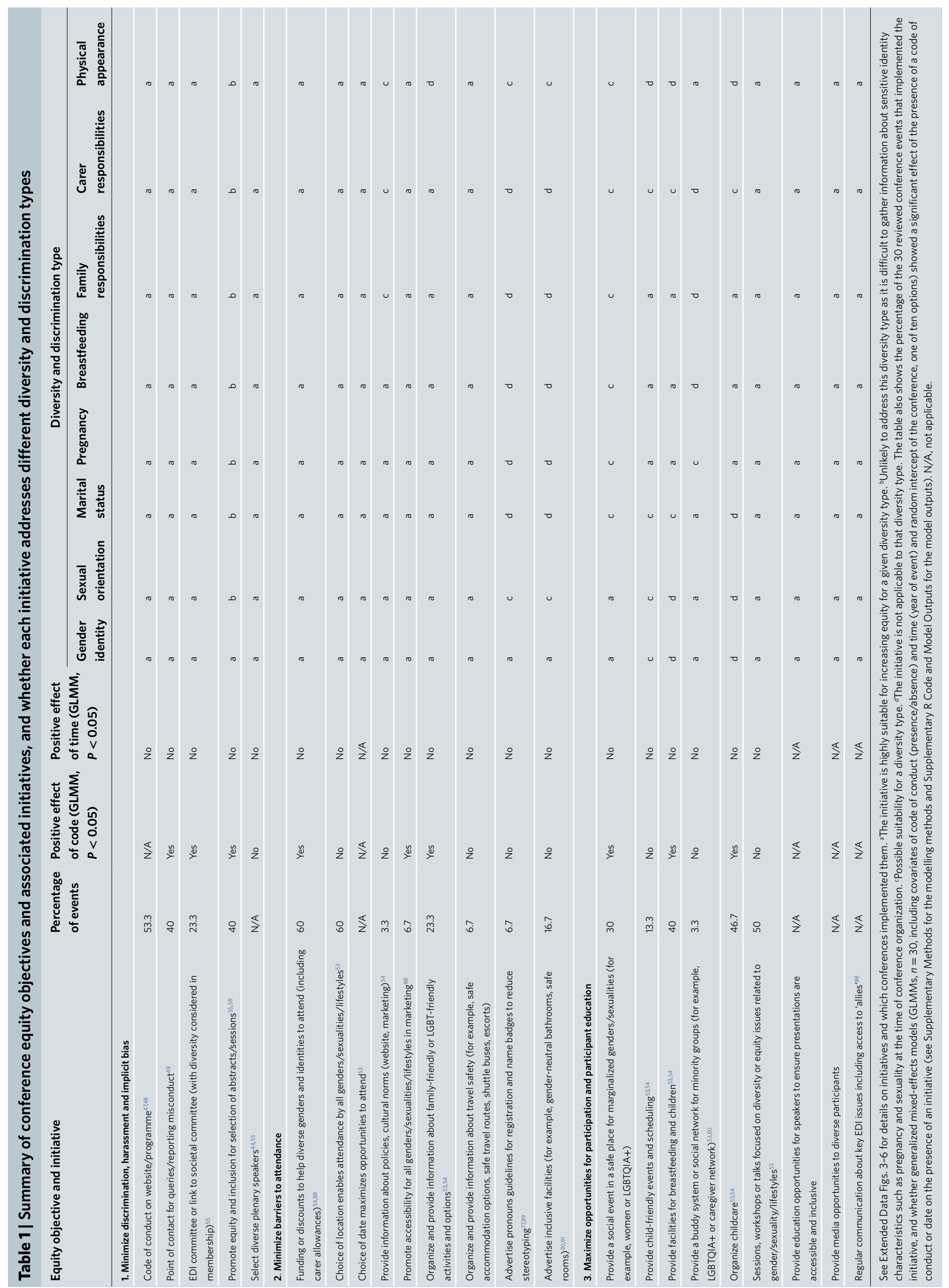




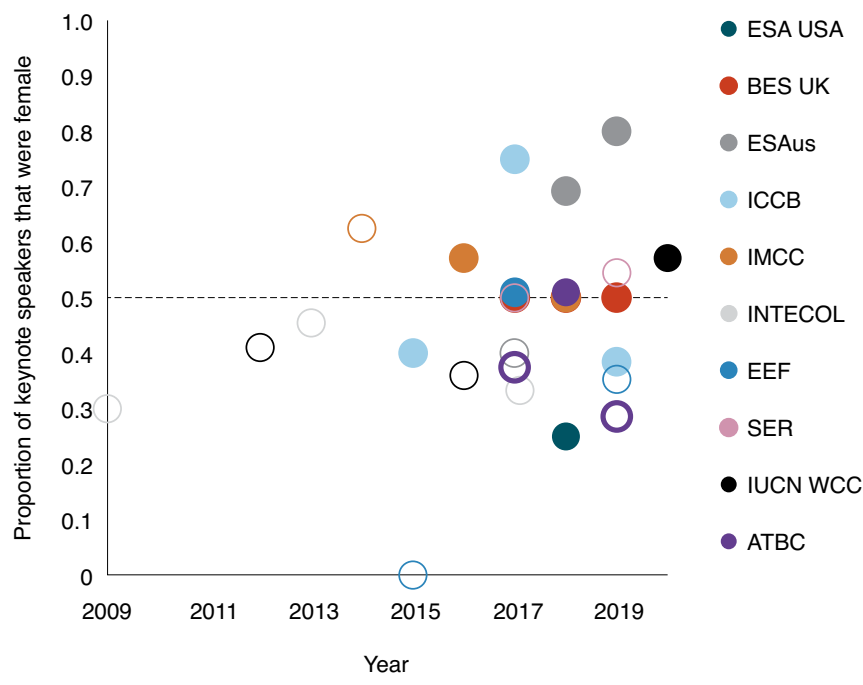

Fig. 2 | The proportion of keynote or plenary speakers who were female at each of the last three events for ten global conferences. Each colour represents a different conference. Conference events with codes of conduct are represented as closed circles and those without codes of conduct as open circles.

developed and clearly communicated a conference code of conduct, with published codes always mentioning gender and sexual orientation and sometimes also referring to marital status, pregnancy or lifestyle (Fig. 1, Extended Data Figs. 2 and 3). Conferences with codes were more likely to have an equity and diversity committee and a point of contact for queries or for reporting discrimination or harassment $(69 \%$ and $7 \%$ of conference events with and without codes respectively; Table 1). An accessible and diverse committee who can answer diversity and equity enquiries during the conference promotion and registration period as well as address issues during the event enables potential participants to be informed (for example, about potential safety problems) and increases attendee confidence that issues will be heard and resolved ${ }^{48}$. It also facilitates changes to scheduling or organization early in the organization process, for instance if event equity or diversity issues are identified by potential attendees and communicated to the committee, and allows important information to be passed to the wider community based on community feedback. Unfortunately, the prevalence of codes, committees and contacts to report equity issues did not increase significantly over the timeline of the review $(P>0.05$ in GLMMs relating the annual proportion of conferences with the initiative to time; Table 1, Extended Data Figs. 3 and 4, and Supplementary R Code and Model Outputs).

Promoting equity and inclusion for selection of abstracts, sessions and plenary speakers ${ }^{55,58}$ is another way to minimize implicit bias and discrimination during conference planning. Diverse speakers are more likely to reflect the underlying diversity of ecology and conservation academics and practitioners ${ }^{59}$, and could also increase productivity by catalysing an exchange of ideas among a broader and more diverse pool of scientists ${ }^{60}$. By publishing guidelines and review criteria to ensure speaker diversity in submitted sessions or workshops, conferences help potential attendees understand the need for diverse speaker panels, and help abstract review panels select sessions that actively address diversity and inclusion issues. Such guidelines were implemented by only a third of conferences and only by those with codes of conduct (Fig. 1, Table 1, Extended Data Fig. 3). For example, the annual BES meetings stipulate that "people proposing thematic sessions at our Annual
Meeting will be given equality and diversity data on our membership and asked to reflect that diversity within the invited speakers they propose." Conversations with conference organizers revealed that some conference organizing committees implemented additional informal initiatives, such as adhering to a 50:50 rule for gender equity in plenary speakers, but these were not made public. Of the 29 out of 30 conference events where plenary speakers could be identified, an average of $47 \%$ ( \pm 17 s.e.m., minimum $=0$, maximum $=80 \%$ ) of the plenary talks were presented by women (Fig. 2). Furthermore, a post-conference survey of $10 \%$ of attendees at the ICCB 2019 in Malaysia reported 50\% female representationalthough it should be noted that some types of surveys attract more female respondents than others ${ }^{61,62}$, and no statistics from actual attendance were available. These numbers are comparable and in general higher than the reported range of $15-35 \%$ female speaker representation for ecology events in the United States between 2000 and $2015^{44}$. However, despite informal and formal procedures for minimizing implicit bias and increasing gender equity in speakers, the proportion of female plenary speakers has not increased during the past ten years, nor did having a code of conduct significantly influence female representation in plenary speakers (GLMM effect sizes: time $=0.012 \pm-0.013(P=0.40)$, code of conduct $=0.131 \pm$ 0.009 ( $P=0.07)$; Fig. 2, Table 1 , and Supplementary R Code and Model Outputs).

\section{Minimizing barriers to conference attendance}

Failure to translate equity and diversity policy into inclusion can be caused by several barriers. The first is event affordability ${ }^{63}$ - people from under-represented groups may face economic barriers such as excessive conference costs and limited scholarship opportunities ${ }^{64}$. The second is event accessibility-the destination is one of the most important factors shaping the decision to attend a conference ${ }^{65,66}$. Conferences that take place in more friendly or accessible locations (for example, those with high acceptance of diverse sexualities) are likely to attract more diverse genders and sexualities, with events held in locations that might be intolerant towards certain minority groups being less attractive ${ }^{63,67,68}$. Additionally, events might exclude people intentionally or unintentionally due to thematic choice, poor planning or inadequate marketing (for example, of the location's image and safety $)^{68,69}$. The third is event amenities-conferences may fail to provide adequate facilities and equipment to support diverse needs ${ }^{63,68,70}$ (see Fig. 3). The fourth is event attitudes-conferences with positive and inclusive attitudes may foster higher participation by people from under-represented groups ${ }^{66,67}$.

The financial cost of attending a conference can be greater for certain genders and sexual orientations due to income disparities and carer responsibilities ${ }^{21,26,71}$. Registration costs for the ecology and conservation conferences represented 1.23 and $1.03 \%$ of the average annual income of gay males ${ }^{21,26,71}$ and male-to-female transgender people ${ }^{72}$ respectively, compared with only $0.72 \%$ of the average annual income (US\$65,000) $)^{73}$ of a heterosexual male conservation scientist in the United States. Initiatives that reduce the financial burden of attending the conference may improve the accessibility of the conference to diverse identities. A range of grants, scholarships and fee reductions to minimize financial barriers to attendance by minority groups are offered by societies. For example, the ATBC offers travel grants to women from a dedicated fund and grants for participants from traditionally under-represented groups. At the 2016 IMCC, all female symposium leads were granted a discount of $20 \%$ as part of an initiative to improve gender equality in marine conservation. At the last three conferences by the ESAus, childcare grants have been offered to assist attendees with children to bring a support carer with them, as well as registration discounts for families with young children where both parents are presenting and sharing childcare responsibility, in recognition that this limits each parent's participation. Even with this range of available initiatives, 
$40 \%$ of conferences offered no initiatives to reduce financial barriers for minority genders or sexual orientations (Extended Data Fig. 4).

Despite decades of studies indicating that location is a critical deciding factor for potential attendees ${ }^{63,67}, 40 \%$ of conferences in ecology and conservation were held in locations that discriminate against a minority gender or sexual orientation. For example, the 2019 ICCB and 2018 IMCC conferences had codes of conduct but were held in Malaysia-a country where homosexuality is a criminal offence. Even when a country has no specific legislations excluding certain identities, the choice of venue can limit attendance. For example, the choice to hold the 2019 ESA in Louisville caused distress in the LGBTQIA+ community due to historical persecution of this community there and perceptions of ongoing discrimination ${ }^{74}$. Choosing an inclusive venue will increase the chance of diverse participants attending if they perceive it to be a safe and affordable environment, free from harassment and discrimination ${ }^{63,67}$. Looking into the legislation for LGBTQIA+ and ethnic minority rights prior to choosing a conference location will ensure that locations with policies discriminating against cultures or sexual and gender identities can be avoided. Similarly, once a location has been chosen, the dates can be selected to ensure that they do not overlap with important social or cultural events (for example, Pride days) that might prevent some members of the scientific community from attending.

Despite many conferences being held in locations known to discriminate against some genders or sexual orientations, few implemented additional initiatives to increase the safety and accessibility of the event and reduce unintentional exclusion of minority groups, beyond providing cursory information about avoiding being alone (Extended Data Fig. 4). For example, at one conference, most evening social events took place outside of the conference venue, requiring more than ten minutes' walk through streets acknowledged by the organizers to be unsafe, with the website recommending that "women avoid isolated locations or traveling alone after dark". A range of initiatives can be implemented to minimize barriers to attendance caused by real or perceived perceptions of event accessibility and safety ${ }^{69}$. These include ensuring that marketing and media activities clearly promote the safety and accessibility of an event for diverse participants, providing web pages dedicated to information on attendee safety during the event, and explaining government policies, visa requirements and cultural norms that may impact certain sexual orientations or genders. These initiatives were rare at ecology and conservation conferences and for most events, having a code of conduct did not influence whether such initiatives were implemented (Table 1). The IMCC was the only conference to provide detailed information to potential attendees about cultural norms and policies in the event location and to clearly promote the accessibility of the event with dedicated pages on its 'IMCC for all' policy, implemented for the first time in $2016^{75}$. When promoting the conference, the website included clear links to accessibility information, volunteers to help participants with specific needs, promotion of mixed-gender restrooms, and family-friendly information pages ${ }^{76}$. Only two events $(7 \%)$ provided information on websites specifically addressing participant safety during the event, describing that shuttle buses would be provided to assist potential attendees with safe

Fig. 3 | Trends in initiatives at ecology and conservation conferences to minimize barriers to attendance and maximize inclusion during the event. $\mathbf{a}$, The proportion of reviewed conferences each year that held a social event specifically targeted at promoting and supporting attendee diversity. $\mathbf{b}$, The proportion offering a session of talks or a workshop specifically about equity, diversity or inclusion in ecology and conservation. c, The proportion of conferences each year offering childcare. $\mathbf{d}, \mathbf{e}$, The proportion offering rooms for parents' needs (d) and the proportion with gender-neutral facilities (for example, mixed-gender bathrooms) or gender-neutral name badges with pronouns guidelines (e). transfer between event locations and accommodation (IMCC 2016 in Canada and ATBC 2019 in Madagascar). Offering affordable, safe accommodation at the conference venue would avoid the need for

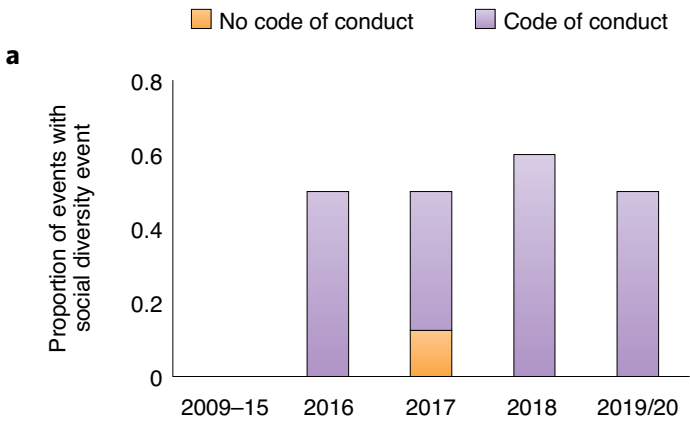

b
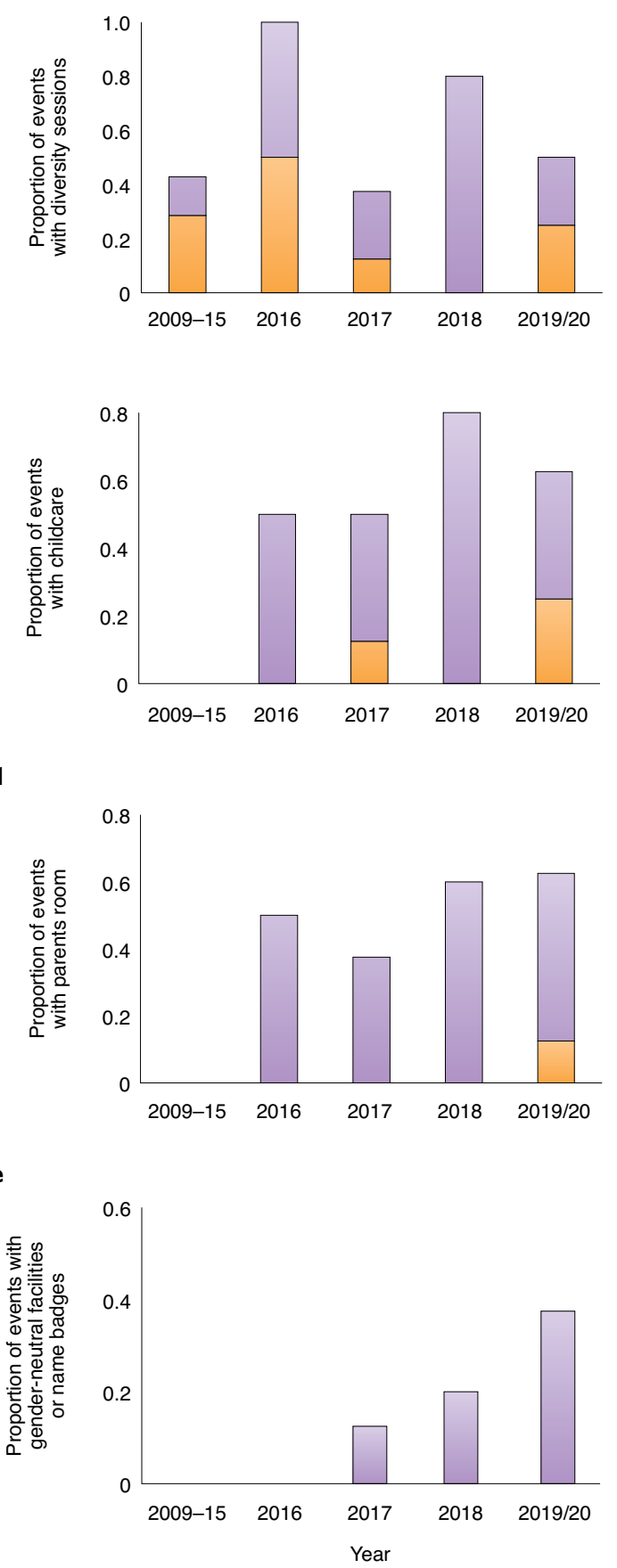


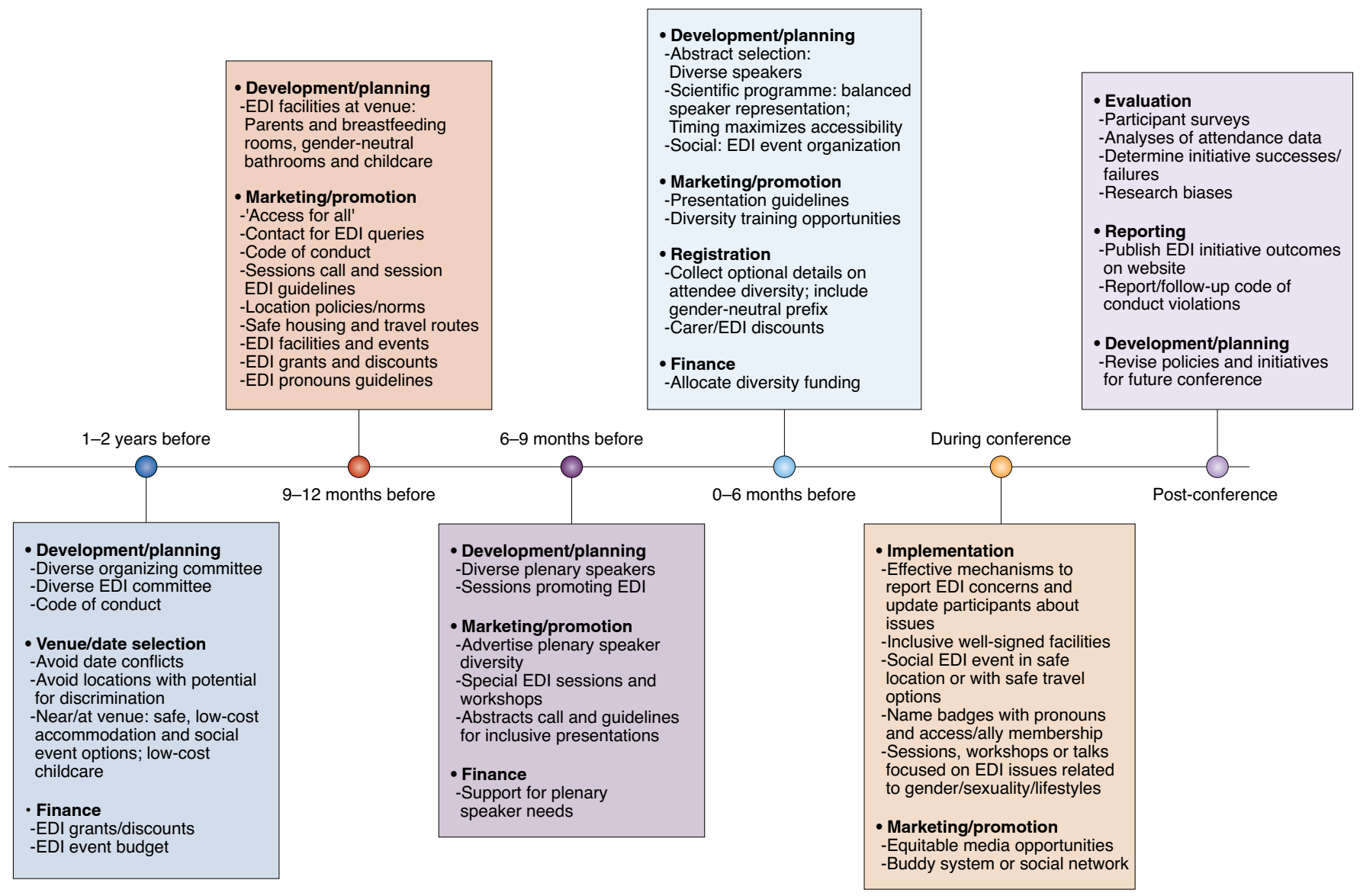

Fig. 4 | Timeline for implementing initiatives to improve equity, diversity and inclusion for diverse genders and sexual orientations at academic ecology and conservation conferences. The timeline highlights initiatives from 1-2 years before the conference through to post-conference initiatives.

shuttle buses to ensure attendee safety. Several conferences offered accommodation options at the conference venue, but in all cases the accommodation at the conference venue was the most expensive option provided, which is likely to discourage low-income and vulnerable minority groups from attending. Other useful initiatives that were not implemented by any conferences include publishing maps of safe walking routes around the conference venue, arranging escorts for vulnerable minority groups, and providing a list of vetted safe accommodation and dining options (for example, LGBTQIA+-friendly hotels).

Marketing and communications of event materials that promote positive, pro-active attitudes towards diversity are likely to lead to higher confidence across diverse genders and sexualities that their needs will be met by the conference ${ }^{63,69}$. Such marketing can start as soon as the conference website is online (Fig. 4). One new initiative to support gender diversity was promoted by the 2019 ESA conference, which encouraged name-tag pronouns to be specified during registration to signal how participants wish to be addressed and reduce unintentional discrimination against non-binary genders ${ }^{77}$.

To promote awareness and support of minority genders and sexualities, many academic workplaces have instituted 'ally' programmes and 'safe zones' that offer training, safe places and support networks ${ }^{78,79}$. Evidence suggests such programmes are related to positive LGBTQIA+ attitudes and increased awareness ${ }^{78,79}$. Several societies have recently implemented conference 'ally' or 'accessibility' networks that participants can choose to join confidentially or publicly (Extended Data Fig. 4). Ideally, members of such a programme would have formal training offered by the society (or be accredited through the ally programmes at their institutions), and members of the group could offer to be a visible diversity and equity presence at a conference for services such as attendee support and advice.

\section{Maximizing opportunities for participation and education}

Implementing policies and actions early in the planning process that increase awareness whilst improving representation of diverse genders and sexual orientations is key to improving inclusion (Fig. 4). Creative ways to incorporate diversity and equity into conference programmes include plenaries and dedicated symposia, workshops focused on teaching attendees specific skills and techniques for inclusive behaviour (for example, inclusive communication for teaching sex and gender in biology), a diversity and inclusion track, formal or informal diversity panel discussions (for example, ICCB 2019's 'Equity, Inclusion, Diversity Sessions' on topics such as 'Addressing Power Imbalances and Combating Harassment and Sexual Assault in Conservation'), or symposia highlighting research that investigates gender diversity in science.

Plenary events attended by all conference participants help to mainstream diversity issues (for example, ATBC 2018's plenary panel on 'Implicit Biases, Diversity, and Inclusion in Tropical Biology and Conservation'), whilst targeted symposia can focus on particular topics (for example, social equity) or challenges. Encouragingly, 50\% of conferences scheduled scientific sessions focused on improving awareness of equity, diversity and inclusion in ecology and conservation, although the frequency of such sessions did not increase over time and was not related to whether a 
conference had a code of conduct (Fig. 3b, Extended Data Fig. 5). Beyond addressing issues of bias and discrimination in academia, there are many opportunities for ecologists and conservation scientists to explicitly investigate diversity and equity in their research. Such research could be stimulated by conferences offering symposia on topics such as finding solutions for linking diversity and inclusion to global Sustainable Development Goals. For example, ESA 2017 offered a special session on 'Causes and strategies for alleviating impacts of environmental change on minority communities', and SER 2017 offered a session on 'Methodological challenges in inclusive ecological restoration: two contrasting case studies from India. Placing diversity and inclusion directly within the scientific programme is key to building awareness of these issues as a mainstream rather than marginalized topic for discussion and research.

In addition to providing awareness and education opportunities in the scientific programme, conferences can also support diversity through ensuring media opportunities attract and promote stories from diverse attendees, and offering events or facilities that cater to specific needs of minority groups. Such initiatives were offered significantly more often by conferences with codes of conduct, but none showed any increase in frequency over time (for results of GLMMs see Supplementary R Code and Model Outputs, and Table 1). For example, $30 \%$ of conferences offered social events to support networking by minority genders and sexualities in a welcoming and inclusive setting, including the BES LGBT mixer and ESA's Diversity Luncheon (Table 1, Fig. 3a) - all but one of these conferences had a code of conduct. Almost $50 \%$ of conferences offered childcare options to attendees and $40 \%$ offered amenities for parents such as breastfeeding rooms (Fig. 3c,d, Extended Data Fig. 5). Previous studies have suggested that social networks targeted towards marginalized groups (for example, a caregiver or LGBTQIA+ network) will improve participation at events ${ }^{53,80}$. Such networks offer a safe place for minority groups to find buddies or people to share accommodation with, to learn from others about how to navigate challenges, or to build confidence when travelling to an unknown destination. One such initiative implemented by the BES is a 'buddy' system for those needing extra assistance during the meeting-some conferences have set up similar programmes of student mentors but have not yet extended the programme to support vulnerable minority groups.

Event programming and timing is also an important consideration for maximizing attendance by diverse identities. Some past conferences start with plenary talks at $8 \mathrm{am}$ (or earlier) and finish at $7 \mathrm{pm}$ or later-this scheduling is exhausting to participants and prohibits many (for example, people with young children, low-income participants commuting to the venue) from participating. In conferences with multiple parallel sessions, symposia on traditionally marginalized subjects often clash with high-profile sessions or speakers, making these topics even more marginalized. Avoiding these kinds of issues will ensure a more inclusive event environment.

\section{Monitoring, evaluating and reporting on initiatives and policy effectiveness}

Without good participant profiling and data retention it is difficult to evaluate the success of initiatives to improve equity and diversity. Few societies collect or retain information on the diversity of sexual orientations and genders at conferences, and no societies have evaluated whether specific initiatives influenced attendee diversity (Extended Data Fig. 6). Of the ten conferences and nine societies contacted, only three societies provided data on attendee diversity. These data were a de-identified list of participant genders and countries of origin derived from participant registration details (ESAus and BES), total breakdowns of conference participants and genders from registration details (ICCB), and a post-hoc survey of conference attendees where attendees provided optional identity data (BES).
There are three reasons for the lack of data of diversity. First, most societies devolve conference organization to small local committees of researchers or to conference organizers who do not retain participant data. Second, data on participant diversity must be provided voluntarily by the participants either during the registration process or in post-hoc surveys, which presents challenges in terms of eliciting and storing sensitive data. Third, even when data on participant diversity are collected, analyses of diversity and initiative effectiveness are challenged by the relatively small size of the LGBTQIA+ community, issues with defining sexual orientation and gender identity, response bias, and concealment of gender or sexual orientation ${ }^{17,81}$. The sensitive nature of sexuality and gender identity questions increase the likelihood that respondents may be untruthful in answers ${ }^{81}$. Unlike status characteristics, such as race and gender, sexual orientation and gender identity may be invisible, with real or perceived stigma in providing this information to conference organizers ${ }^{34,35}$.

The lack of data on conference attendee diversity and experiences is a critical gap to improving conference inclusion and equity ${ }^{30}$. Best practice guides have been developed to help collect sensitive information in a way that reduces response bias and increases confidence by respondents that data will be treated in a sensitive manner ${ }^{82}$. Societies should stress that answering questions is voluntary, in addition to explaining that providing this information would be helpful to addressing conference inequity. Continuous examination of the success and failure of initiatives is critical to improve outcomes (Fig. 4). Conferences can use existing diversity initiatives such as the Athena Swan Charter to set up an equity, diversity and inclusion action plan with an effective monitoring and reporting process ${ }^{10,13}$. Effective evaluation requires a team responsible for embedding and operationalizing actions (for example, an equity, diversity and inclusion committee), and an assessment process led either by the organizing committee or a societal working group. Having assessment conducted by a societal working group rather than the organizing committee removes possible subjectivity from self-assessment and ensures consistency across conference events (as committees change from year to year). As for the Athena Swan Charter, protocols for assessing implementation of the equity, diversity and inclusion action plan should include benchmarks and success criteria. In addition to learning how different initiatives might increase the number of attendees from minority groups, societies could also use participant surveys (for example, eliciting perceptions and experiences before, during and/or after the conference) and registration data to study bias or incivility against under-represented groups, analyse its scope and severity, and report on efforts to eliminate the issue.

\section{Moving towards more equitable and inclusive conservation and ecology conferences}

For transparency and awareness building, conferences should document and promote the actions they take to improve equity, diversity and inclusion, even if those actions are minimal. Setting out the policies and actions to be taken throughout the timeline of organizing and running the conference, and providing clear guidelines for organizing committees to follow, will help ensure that initiatives are implemented in a timely manner (for example, Fig. 4). Academic societies can facilitate consistent practices by retaining participation and event attendance data post-conference and evaluating the success or failure of alternative initiatives.

While it is important to consider multiple strategies to recruit more minority participants at conferences, it is most important to understand and address the barriers preventing minority groups from participating. Economic barriers are one of the most common drivers of non-participation in conferences ${ }^{83,84}$. Recent suggestions to enable more equitable participation in global conferences include virtual conferencing, or to offer online access to all presentations 
with discounted fees for online attendance ${ }^{85}$. These options have become a reality during 2020's global coronavirus pandemic and lockdown. However, many argue that virtual technology can never truly replicate the social interactions required for effective networking $^{86}$. It may be harder to build meaningful relationships with new people without face-to-face interactions at a conference. During the current hiatus in physical conferencing, we have the opportunity to rethink how we conduct conferences, and to move to a model that better supports equity, diversity and inclusion.

This review found that most societies running international ecology and conservation conferences have implemented some initiatives to make them more accessible to diverse gender identities and sexual orientations, and that codes of conduct are significantly linked to the occurrence of some initiatives (for results of GLMMs see Supplementary R Code and Model Outputs, and Table 1). Codes are more likely to be associated with structural fixes such as committees and points of contact for equity, diversity and inclusion (EDI) concerns, or initiatives specifically focused towards parents such as offering breastfeeding facilities and childcare (for results of GLMMs see Supplementary R Code and Model Outputs, and Table 1). Regrettably, despite the presence of codes of conduct across more than $50 \%$ of conference events, such codes are not achieving their intended goals, as they have no correlation with the implementation of half of the diversity initiatives reviewed in this study (Table 1), and thus far have not resulted in significantly higher representation of genders across speakers (for results of GLMMs see Supplementary R Code and Model Outputs, and Fig. 2). Initiatives supporting equity and diversity across sexual orientations and gender identities are inconsistent and variable even across conferences run by the same society (Extended Data Figs. 3-6).

There are ethical and social justice concerns when groups are excluded from participating fully in science. Identity-based discrimination and exclusion reduce both the creativity and productivity of science $^{37}$. Studies have suggested that diverse groups of people bring diverse and creative ideas and ways of thinking to the scientific process and practice ${ }^{87}$. Making conference codes of conduct and equity reporting procedures apparent and easily accessible online and during the event is only the first step towards inclusion ${ }^{48}$. Conferences must also achieve tangible outcomes for equity, diversity and inclusion, through advocating and supporting the needs and experiences of historically marginalized and discriminated groups. Progress in inclusion starts from day one of conference planning and development activities (Fig. 4), and requires reducing barriers such as affordability and perceived or actual discrimination issues (for example, location choice, facilities and safety), allocating appropriate finances to support the needs of minority groups, and ensuring conference accessibility and inclusion is not only promoted but also backed by real initiatives. Discrimination and harassment persist in conservation and ecology conferences despite well-meaning codes of conduct. Conference attendees experience both perceived and actual incivility, sexist climates, bullying, ostracism and injustice $e^{30,46}$. Addressing these issues requires informed consideration of how to communicate and support acceptance in a positive working conference environment ${ }^{30}$. Policies to manage diversity (for example, aiming to increase numbers of speakers from marginalized groups) may reduce public discrimination but are ineffective at improving psychological outcomes for marginalized groups such as the LGBTQIA+ community if barriers exclude attendees from opportunities or if perceived injustices and incivility persist ${ }^{17}$. The lack of concrete knowledge on the execution and effectiveness of initiatives means that we still do not understand how, when or why some initiatives are likely to succeed or fail. Improved conference evaluation and reporting is needed to inform and educate both the societies running the conferences and the attendees participating in them. The ideal is a professional conference that does not need a diversity and inclusion track or committee; attendee diversity and equity are supported and managed throughout the organization and running of the conference by both organizers and participants, delivering an inclusive environment for all.

\section{Data availability}

All data are available on figshare (https://doi.org/10.6084/ m9.figshare.12471464.v1).

Received: 19 December 2019; Accepted: 23 June 2020;

Published online: 3 August 2020

\section{References}

1. O'Brien, K. R. et al. What is gender equality in science? Trends Ecol. Evol. 34 395-399 (2019)

2. Yoder, J. B. \& Mattheis, A. Queer in STEM: workplace experiences reported in a national survey of LGBTQA individuals in science, technology, engineering, and mathematics careers. J. Homosex. 63, 1-27 (2016).

3. Larivière, V., Ni, C., Gingras, Y., Cronin, B. \& Sugimoto, C. R. Bibliometrics: global gender disparities in science. Nature 504, 211-213 (2013).

4. Ellis, S. J. Diversity and inclusivity at university: a survey of the experiences of lesbian, gay, bisexual and trans (LGBT) students in the UK. High. Educ. 57, 723-739 (2008)

5. Rumens, N. \& Kerfoot, D. Gay men at work: (re)constructing the self as professional. Hum. Relat. 62, 763-786 (2009).

6. Pew Research Center Global Attitudes Project Gender Equality Universally Embraced, but Inequalities Acknowledged (Pew Research Center, 2010).

7. O’Brien, K. R., Martinez, L. R., Ruggs, E. N., Rinehart, J. \& Hebl, M. R. Policies that make a difference: bridging the gender equity and work-family gap in academia. Gend. Manag. 30, 414-426 (2015).

8. Hirsh, E. \& Cha, Y. Mandating change. ILR Rev. 70, 42-72 (2016).

9. Kanowitz, L. Sex-based discrimination in American law III: Title VII of the 1964 Civil Rights Act and the Equal Pay Act of 1963. Hastings Law J. 20, 305-360 (1968).

10. Ovseiko, P. V., Chapple, A., Edmunds, L. D. \& Ziebland, S. Advancing gender equality through the Athena SWAN Charter for Women in Science: an exploratory study of women's and men's perceptions. Health Res. Policy Syst. 15, 12 (2017).

11. Winchester, H. P. M. \& Browning, L. Gender equality in academia: a critical reflection. J. High. Educ. Policy Manag. 37, 269-281 (2015).

12. Chang, J., Connell, J., Burgess, J. \& Travaglione, A. Gender wage gaps in Australian workplaces: are policy responses working? Equal. Divers. Incl. 33, 764-775 (2014)

13. Rosser, S. V., Barnard, S., Carnes, M. \& Munir, F. Athena SWAN and ADVANCE: effectiveness and lessons learned. Lancet 393, 604-608 (2019).

14. Smith, J. L., Handley, I. M., Zale, A. V., Rushing, S. \& Potvin, M. A. Now hiring! Empirically testing a three-step intervention to increase faculty gender diversity in STEM. BioScience 65, 1084-1087 (2015).

15. European Commission She Figures 2009: Statistics and Indicators on Gender Equality in Science (European Communities, 2009).

16. Kuyper, L. Differences in workplace experiences between lesbian, gay, bisexual, and heterosexual employees in a representative population study. Psychol. Sex. Orientat. Gend. Divers. 2, 1-11 (2015).

17. Lloren, A. \& Parini, L. How LGBT-supportive workplace policies shape the experience of lesbian, gay men, and bisexual employees. Sex. Res. Soc. Policy 14, 289-299 (2016).

18. Klawitter, M. Meta-analysis of the effects of sexual orientation on earnings. Ind. Relat. 54, 4-32 (2015).

19. Aksoy, C. G., Carpenter, C. S. \& Frank, J. Sexual orientation and earnings: new evidence from the United Kingdom. ILR Rev. 71, 242-272 (2017).

20. Antecol, H., Jong, A. \& Steinberger, M. The sexual orientation wage gap: the role of occupational sorting and human capital. ILR Rev. 61, 518-543 (2008).

21. Blandford, J. M. The nexus of sexual orientation and gender in the determination of earnings. ILR Rev. 56, 622-642 (2016).

22. Ozeren, E. Sexual orientation discrimination in the workplace: a systematic review of literature. Procedia 109, 1203-1215 (2014).

23. Cech, E. A. LGBT professionals' workplace experiences in STEM-related federal agencies. In Proc. 2015 Am. Soc. Eng. Educ. Natl Conf. 26.1094.1-26.1094.10 https://doi.org/10.18260/p.24431 (ASEE, 2015).

24. Cech, E. A. \& Pham, M. V. Queer in STEM organizations: workplace disadvantages for LGBT employees in STEM related federal agencies. Soc. Sci. 6, 12 (2017).

25. Freeman, J. LGBTQ scientists are still left out. Nature 559, 27-28 (2018).

26. Sabia, J. J., Wooden, M. \& Nguyen, T. T. Sexual identity, same-sex relationships, and labour market dynamics: new evidence from longitudinal data in Australia. South. Econ. J. 83, 903-931 (2017).

27. Bridges, S. \& Mann, S. Sexual orientation, legal partnerships and wages in Britain. Work Employ. Soc. 33, 1020-1038 (2019). 
28. Schendel, R. \& McCowan, T. Expanding higher education systems in low- and middle-income countries: the challenges of equity and quality. High. Educ. 72, 407-411 (2016).

29. Moss-Racusin, C. A., Dovidio, J. F., Brescoll, V. L., Graham, M. J. \& Handelsman, J. Science faculty's subtle gender biases favor male students. Proc. Natl Acad. Sci. USA 109, 16474-16479 (2012).

30. Settles, I. H. \& O'Connor, R. C. Incivility at academic conferences: gender differences and the mediating role of climate. Sex. Roles 71, 71-82 (2014)

31. Bilimoria, D. \& Stewart, A. J. "Don't ask, don't tell": the academic climate for lesbian, gay, bisexual, and transgender faculty in science and engineering. NWSA J. 21, 85-103 (2009).

32. Huebner, D. M. \& Davis, M. C. Perceived antigay discrimination and physical health outcomes. Health Psychol. 26, 627-634 (2007).

33. Carr, P. L. et al. A summary report from the research partnership on women in science careers. J. Gen. Intern. Med. 34, 356-362 (2019).

34. Clair, J. A., Beatty, J. E. \& Maclean, T. L. Out of sight but not out of mind: managing invisible social identities in the workplace. Acad. Manag. Rev. 30, 78-95 (2005).

35. Ragins, B. R., Singh, R. \& Cornwell, J. M. Making the invisible visible: fear and disclosure of sexual orientation at work. J. Appl. Psychol. 92, 1103-1118 (2007).

36. Shaw, A. K. \& Stanton, D. E. Leaks in the pipeline: separating demographic inertia from ongoing gender differences in academia. Proc. Biol. Sci. 279, 3736-3741 (2012).

37. Astegiano, J., Sebastian-Gonzalez, E. \& Castanho, C. T. Unravelling the gender productivity gap in science: a meta-analytical review. $R$. Soc. Open Sci. 6, 181566 (2019).

38. Badgett, M., Durso, L. E., Mallory, C. \& Kastanis, A. The Business Impact of LGBT-Supportive Workplace Policies (The Williams Institute, 2013).

39. de Leon, F. L. L. \& McQuillin, B. The role of conferences on the pathway to academic impact. J. Hum. Resour. 55, 164-193 (2020).

40. Oester, S., Cigliano, J. A., Hind-Ozan, E. J. \& Parsons, E. C. M. Why conferences matter-an illustration from the International Marine Conservation Congress. Front. Mar. Sci. 4, 257 (2017).

41. Damschen, E. I. et al. Visibility matters: increasing knowledge of women's contributions to ecology. Front. Ecol. Environ. 3, 212-219 (2005).

42. Isbell, L. A., Young, T. P. \& Harcourt, A. H. Stag parties linger: continued gender bias in a female-rich scientific discipline. PLoS ONE 7, e49682 (2012).

43. King, L. et al. Diversity in geoscience: participation, behaviour, and the division of scientific labour at a Canadian geoscience conference. Facets 3 , 415-440 (2018).

44. Farr, C. M. et al. Addressing the gender gap in distinguished speakers at professional ecology conferences. BioScience 67, 464-468 (2017).

45. Karpowitz, C. F., Mendelberg, T. \& Shaker, L. Gender inequality in deliberative participation. Am. Political Sci. Rev. 106, 533-547 (2012).

46. Hinsley, A., Sutherland, W. J. \& Johnston, A. Men ask more questions than women at a scientific conference. PLoS ONE 12, e0185534 (2017).

47. Favaro, B. et al. Your science conference should have a code of conduct. Front. Mar. Sci. 3, 103 (2016).

48. Foxx, A. J. et al. Evaluating the prevalence and quality of conference codes of conduct. Proc. Natl Acad. Sci. USA 116, 14931-14936 (2019).

49. Adams, J. S., Tashchian, A. \& Shore, T. H. Codes of ethics as signals for ethical behavior. J. Bus. Ethics 29, 199-211 (2001)

50. Verschuuren, B. An overview of cultural and spiritual values in ecosystem management and conservation strategies. In International Conference on Endogenous Development and Bio-Cultural Diversity 299-325 (TEEB Oceans, 2006).

51. Halpern, B. S. et al. Achieving the triple bottom line in the face of inherent trade-offs among social equity, economic return, and conservation. Proc. Natl Acad. Sci. USA 110, 6229-6234 (2013).

52. Agarwal, B. Gender equality, food security and the sustainable development goals. Curr. Opin. Environ. Sustain. 34, 26-32 (2018).

53. Bos, A. L., Sweet-Cushman, J. \& Schneider, M. C. Family-friendly academic conferences: a missing link to fix the "leaky pipeline"? Politics Groups Ident. 7, 748-758 (2019).

54. Calisi, R. M., a Working Group of Mothers in Science. Opinion: how to tackle the childcare-conference conundrum. Proc. Natl Acad. Sci. USA 115, 2845-2849 (2018).

55. Debarre, F., Rode, N. O. \& Ugelvig, L. V. Gender equity at scientific events. Evol. Lett. 2, 148-158 (2018).

56. Parsons, E. C. M. So you think you want to run an environmental conservation meeting? Advice on the slings and arrows of outrageous fortune that accompany academic conference planning. J. Environ. Stud. Sci. 5, 735-744 (2015).

57. Potvin, D. A., Burdfield-Steel, E., Potvin, J. M. \& Heap, S. M. Diversity begets diversity: a global perspective on gender equality in scientific society leadership. PLoS ONE 13, e0197280 (2018).

58. Klein, R. S. et al. Speaking out about gender imbalance in invited speakers improves diversity. Nat. Immunol. 18, 475-478 (2017).
59. Hagan, A. K., Pollet, R. M. \& Libertucci, J. Suggestions for improving invited speaker diversity to reflect trainee diversity. J. Microbiol. Biol. Educ. 21, 1-9 (2020).

60. Campbell, L. G., Mehtani, S., Dozier, M. E. \& Rinehart, J. Gender-heterogeneous working groups produce higher quality science. PLoS ONE 8, e79147 (2013).

61. Van Mol, C. Improving web survey efficiency: the impact of an extra reminder and reminder content on web survey response. Int. J. Soc. Res. Methodol. 20, 317-327 (2016).

62. Curtin, R., Presser, S. \& Singer, E. The effects of response rate changes on the index of consumer sentiment. Public Opin. Q. 64, 413-428 (2000).

63. Oppermann, M. \& Chon, K.-S. Convention participation decision-making process. Ann. Tour. Res. 24, 178-191 (1997).

64. Grant, J. M. et al. Injustice at Every Turn: A Report of the National Transgender Discrimination Survey (National Center for Transgender Equality and National Gay and Lesbian Task Force, 2011).

65. Borghans, L., Romans, M. \& Sauermann, J. What makes a good conference? Analysing the preferences of labour economists. Lab. Econ. 17, 868-874 (2010)

66. Yoo, J. J.-E. \& Chon, K. Factors affecting convention participation decision-making: developing a measurement scale. J. Travel Res. 47 113-122 (2008)

67. Lee, T. H. \& Park, J.-Y. Study on the degree of importance of convention service factors. J. Conv. Exhib. Manag. 3, 69-85 (2008).

68. Terzi, M. C., Sakas, D. P. \& Seimenis, I. International events: the impact of the conference location. Procedia 73, 363-372 (2013).

69. Oppermann, M. Convention destination images: analysis of association meeting planners' perceptions. Tour. Manag. 17, 175-182 (1996).

70. Zhang, H. Q., Leung, V. \& Qu, H. A refined model of factors affecting convention participation decision-making. Tour. Manag. 28, 1123-1127 (2007).

71. Sears, B. \& Mallory, C. Documented Evidence of Employment Discrimination \& its Effects on LGBT People (The Williams Institute, 2011).

72. Schilt, K. \& Wiswall, M. Before and after: gender transitions, human capital, and workplace experiences. BE J. Econ. Anal. Policy 8, 39 (2008).

73. Sargent Jr, J. F. The US Science and Engineering Workforce: Recent, Current, and Projected Employment, Wages, and Unemployment CRS Report R43061 (Congressional Research Service, 2017).

74. Issues Surrounding Louisville as an ESA Meeting Site (McEwan Lab, 2019); https://go.nature.com/2CVH6Yk

75. IMCC for All (Society for Conservation Biology, 2016); https://go.nature. $\mathrm{com} / 31 \mathrm{uHVBz}$

76. Bringing the Family to IMCC4 (Society for Conservation Biology, 2016); https://go.nature.com/2NKoHjn

77. Why Should I Put My Pronouns on My Name Tag? (Ecological Society of America, 2019); https://go.nature.com/3g9sO4H

78. Poynter, K. J. \& Tubbs, N. J. Safe zones. J. LGBT Youth 5, 121-132 (2008).

79. Worthen, M. G. F. College student experiences with an LGBTQ ally training program: a mixed methods study at a university in the southern United States. J. LGBT Youth 8, 332-377 (2011).

80. Duggan, M., Lenhart, A., Lampe, C. \& Ellison, N. B. Parents and Social Media (Pew Research Center, 2015).

81. Waite, S. \& Denier, N. A research note on Canada's LGBT data landscape: where we are and what the future holds. Can. Rev. Sociol. 56, 93-117 (2019).

82. Badgett, M. V. L. Best Practices for Asking Questions about Sexual Orientation on Surveys (The Williams Institute, 2009).

83. Hong, A. \& Anderson, D. H. Barriers to participation for Latino people at Dodge Nature Center. J. Environ. Educ. 37, 33-44 (2006).

84. Van Dyck, D., Cardon, G., De Bourdeaudhuij, I., de Ridder, L. \& Willem, A. Who participates in running events? Socio-demographic characteristics, psychosocial factors and barriers as correlates of non-participation-a pilot study in Belgium. Int. J. Environ. Res. Public Health 14, 1315 (2017).

85. Fraser, H., Soanes, K., Jones, S. A., Jones, C. S. \& Malishev, M. The value of virtual conferencing for ecology and conservation. Conserv. Biol. 31, 540-546 (2017).

86. De Pillis, E. \& Furumo, K. Virtual vs. face-to-face teams: deadbeats, deserters, and other considerations. In Proc. 2006 ACM SIGMIS CPR conference on computer personnel research: Forty four years of computer personnel research: achievements, challenges \& the future 318-320 (Association for Computing Machinery, 2006).

87. Nielsen, M. W. et al. Opinion: gender diversity leads to better science. Proc. Natl Acad. Sci. USA 114, 1740-1742 (2017).

88. Finkel, R., Sharp, B. \& Sweeney, M. Accessibility, Inclusion, and Diversity in Critical Event Studies (Routledge, 2018).

89. Sczesny, S., Formanowicz, M. \& Moser, F. Can gender-fair language reduce gender stereotyping and discrimination? Front. Psychol. 7, 25 (2016).

90. Campbell, J. E. Gay, Lesbian, Bisexual, and Transgender Students: Wants and Needs Concerning Gender-Neutral Housing. MA thesis, California State Univ. (2012). 
91. Molotch, H. \& Norén, L. Toilet: Public Restrooms and the Politics of Sharing (NYU Press, 2010).

\section{Acknowledgements}

I thank the Society for Conservation Biology, Ecological Society of Australia and British Ecological Society for sharing anonymous data on attendee diversity at conferences. I. Chades and V. McShane provided feedback on earlier drafts. A.I.T.T. is supported by an Australian Research Council Discovery Early Career Researcher Award.

\section{Competing interests}

The author declares no competing financial interests. The author has a non-financial competing interest with the Ecological Society of Australia (unpaid member and voluntary Board position), the Society for Conservation Biology (unpaid member), and the British Ecological Society (unpaid member and Associate Editor of BES journal).

\section{Additional information}

Extended data is available for this paper at https://doi.org/10.1038/s41559-020-1255-x. Supplementary information is available for this paper at https://doi.org/10.1038/ s41559-020-1255-X

Correspondence should be addressed to A.I.T.T.

Reprints and permissions information is available at www.nature.com/reprints. Publisher's note Springer Nature remains neutral with regard to jurisdictional claims in published maps and institutional affiliations.

(c) Springer Nature Limited 2020 


\begin{tabular}{|c|c|}
\hline Term & Definition \\
\hline Diversity & $\begin{array}{l}\text { The visible and invisible differences that exist between people, including (but } \\
\text { not limited to) race, physical appearance, sex, sexual orientation, gender } \\
\text { identity, lawful sexual activity, age, physical or mental disability, marital status, } \\
\text { family responsibilities, pregnancy, breast feeding, carer responsibilities, } \\
\text { religion, political opinion, national extraction, social origin, industrial activity, } \\
\text { military status or society/union membership. It also refers to diverse ways of } \\
\text { thinking and ways of working. }\end{array}$ \\
\hline Inclusion & $\begin{array}{l}\text { Ensuring that current, future and potential conference participants (including } \\
\text { volunteers, exhibitors and attendees) have equality of opportunity without } \\
\text { any barriers or obstacles as a result of personal characteristics such as race, } \\
\text { gender, religion or social origin. }\end{array}$ \\
\hline Equity & $\begin{array}{l}\text { The principle and process of fairness. It ensures that all people's rights, } \\
\text { responsibilities and opportunities do not depend on their personal } \\
\text { characteristics such as gender, religion, language, culture or socio-economic } \\
\text { origin. Equity-what is fair and just-may not reflect strict equality-what is } \\
\text { applied, allocated, or distributed equally. Equity encompasses models and } \\
\text { strategies that may be considered fair and equivalent in terms of rights, } \\
\text { benefits, obligations, and opportunities, but not necessarily equal. }\end{array}$ \\
\hline Code of Conduct & $\begin{array}{l}\text { A statement providing clear guidelines for ethical behaviour. When followed, } \\
\text { codes guide productive and acceptable behaviour and create an inclusive } \\
\text { environment that welcomes all people. Codes of Conduct often include } \\
\text { standards of behaviour, e.g. to eliminate sexual misconduct. }\end{array}$ \\
\hline Gender identity & $\begin{array}{l}\text { Your own, internal, personal sense of being male, female, or outside of that } \\
\text { gender binary (i.e. non-binary). }\end{array}$ \\
\hline Sexual orientation & $\begin{array}{l}\text { A person's enduring physical, romantic, and/or emotional attraction to } \\
\text { another person (for example: straight, gay, lesbian, bisexual). }\end{array}$ \\
\hline
\end{tabular}

Extended Data Fig. 1 | Supplementary glossary of equity, diversity and inclusion terms. Terms and definitions used to describe equity, diversity and inclusion in relation to sexual orientation and gender identity in Codes of Conduct for academic conferences. 


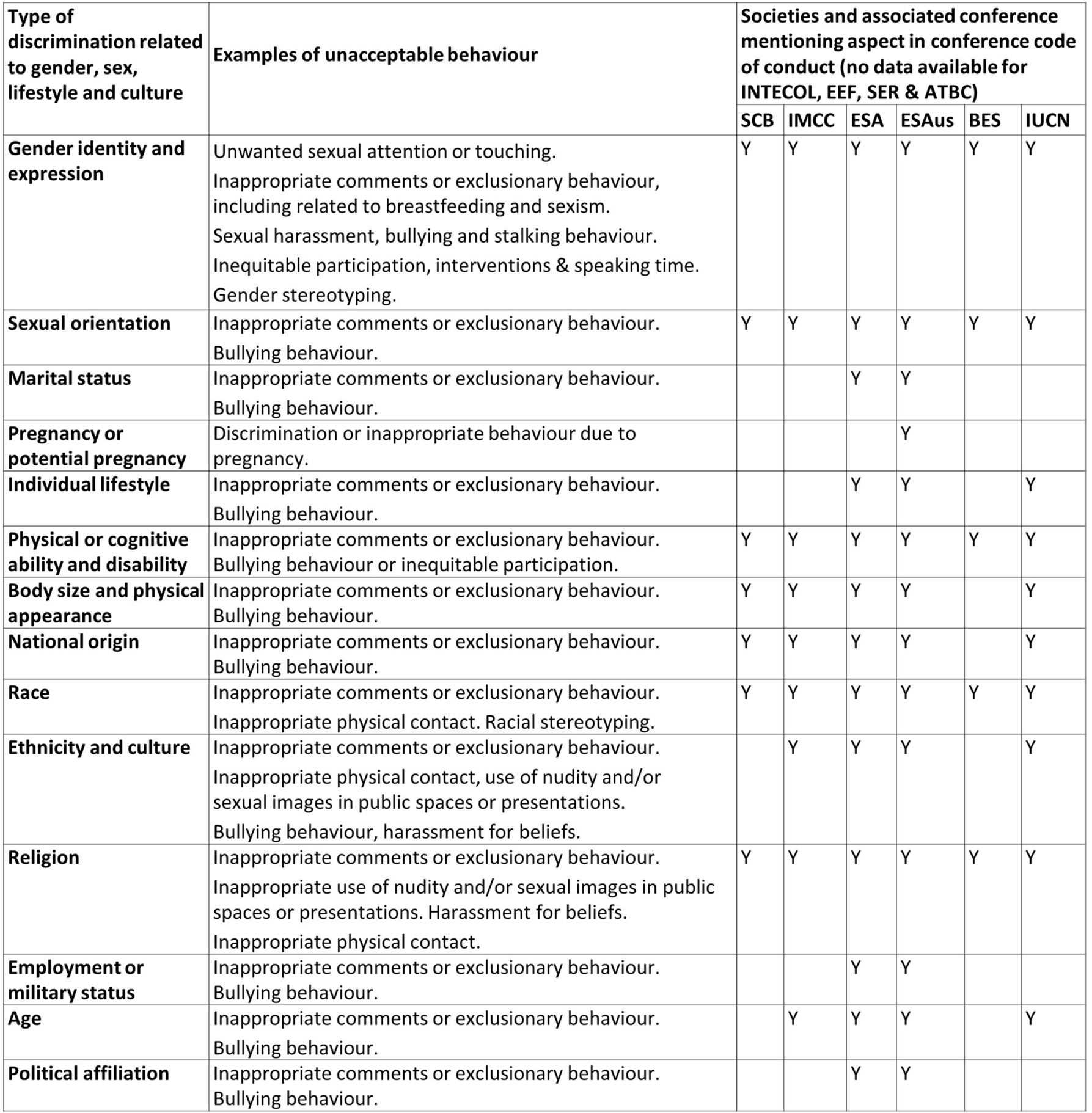

Extended Data Fig. 2 | Supplementary table showing types of discrimination identified in Codes of Conduct for international ecology and conservation conferences. Qualitative content analysis of codes of conduct for international ecology and conservation conferences to identify different types of identity-based discrimination. Conferences and years reviewed were the biannual International Congress for Conservation Biology (ICCB, 2015-2019), International Marine Conservation Congress (IMCC, 2014-2018), European Ecological Federation (EEF) Conference (2015-2019) and Society for Ecological Restoration (SER) World Conference on Ecological Restoration (2015-2019), annual conferences of the Ecological Society of America (ESA, 2017-2019), Ecological Society of Australia (ESAus, 2017-2019), British Ecological Society (BES, 2017-2019) and Association for Tropical Biology and Conservation (ATBC, 2017-2019), the conference of the International Association for Ecology (INTECOL, 2009-2017), and the IUCN World Conservation Congress (WCC) held once every 4 years (2012-2020). 


\begin{tabular}{|c|c|c|c|c|c|c|c|c|c|c|c|c|}
\hline \multicolumn{2}{|c|}{$\begin{array}{l}\text { Discrimination \& } \\
\text { associated action }\end{array}$} & $\begin{array}{l}\text { ESA } \\
\text { USA }\end{array}$ & $\begin{array}{l}\text { BES } \\
\text { UK }\end{array}$ & $\begin{array}{l}\text { ESA } \\
\text { Aus }\end{array}$ & ICCB & IMCC & $\begin{array}{c}\text { INTE- } \\
\text { COL }\end{array}$ & EEF & SER & $\begin{array}{l}\text { IUCN } \\
\text { WCC }\end{array}$ & АТBC & Checklist \\
\hline \multirow{12}{*}{ 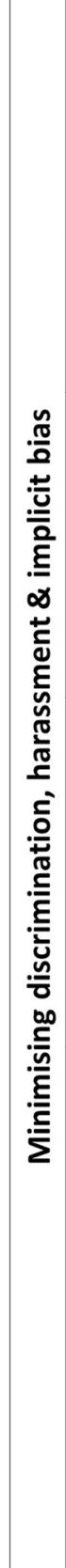 } & \multirow{3}{*}{$\begin{array}{l}\text { Code of conduct } \\
\text { (or similar } \\
\text { policy) on } \\
\text { website/ } \\
\text { program }\end{array}$} & & & & & & & & & & & $\begin{array}{l}\text {-Is there a policy \& code of conduct that } \\
\text { explicitly sets out different kinds of } \\
\text { discrimination \& consequences for } \\
\text { misconduct, including a way to report } \\
\text { violations? }\end{array}$ \\
\hline & & & & & & & & & & & & $\begin{array}{l}\text { Does EDI policy include all types of } \\
\text { diversity? }\end{array}$ \\
\hline & & & & & & & & & & & & $\begin{array}{l}\text {-Is EDI policy clearly identified on } \\
\text { conference website? }\end{array}$ \\
\hline & \multirow{3}{*}{$\begin{array}{l}\text { Clear point of } \\
\text { contact for } \\
\text { queries/ } \\
\text { reporting } \\
\text { misconduct } \\
\end{array}$} & & & & & & & & & & & $\begin{array}{l}\text { Has organising committee decided on a } \\
\text { clear point of contact for EDI concerns? }\end{array}$ \\
\hline & & & & & & & & & & & & $\begin{array}{l}\text {-Is contact person for EDI queries clearly } \\
\text { identified in marketing \& on website? }\end{array}$ \\
\hline & & & & & & & & & & & & $\begin{array}{l}\text {-Is contact person for EDI queries } \\
\text { adequately trained to address EDI } \\
\text { concerns? }\end{array}$ \\
\hline & \multirow{3}{*}{$\begin{array}{l}\text { EDI committee } \\
\text { or clear link to } \\
\text { societal } \\
\text { committee }\end{array}$} & & & & & & & & & & & $\begin{array}{l}\text { Does the organising committee include } \\
\text { diverse representation across genders, } \\
\text { employment, biocultural identities \& other } \\
\text { personal characteristics? }\end{array}$ \\
\hline & & & & & & & & & & & & $\begin{array}{l}\text { Is there a subcommittee for conference } \\
\text { EDI (with diverse membership)? }\end{array}$ \\
\hline & & & & & & & & & & & & $\begin{array}{l}\text { · Have EDI committee roles \& } \\
\text { responsibilities been determined? }\end{array}$ \\
\hline & \multirow{3}{*}{$\begin{array}{l}\text { Promote equity } \\
\& \text { inclusion for } \\
\text { selection of } \\
\text { abstracts/ } \\
\text { sessions }\end{array}$} & & & & & & & & & & & $\begin{array}{l}\text {-Are at least } 50 \% \text { of invited panel/plenary } \\
\text { speakers from minorities (female, } \\
\text { indigenous, LGBTQIA+, developing } \\
\text { nations)? }\end{array}$ \\
\hline & & & & & & & & & & & & $\begin{array}{l}\text { Is speaker diversity promoted for sessions } \\
\& \text { are guidelines provided to those } \\
\text { submitting abstracts or sessions to } \\
\text { promote equity \& diversity? }\end{array}$ \\
\hline & & & & & & & & & & & & $\begin{array}{l}\text {-Is EDI a criterion for evaluating symposia, } \\
\text { oral \& poster sessions \& workshops, with } \\
\text { guidelines for review (e.g. include diversity } \\
\text { statement in application)? }\end{array}$ \\
\hline
\end{tabular}

Extended Data Fig. 3 | Supplementary table of supporting information for Table 1, showing initiatives targeted towards "Minimising discrimination, implicit bias and harassment". Summarizes equity, diversity and inclusion initiatives for 30 events held by 10 ecology and conservation conferences, and checklist associated with each initiative to promote its implementation. Dark grey indicates that the initiative was implemented. Light grey indicates that the initiative was not advertised but known to have been implemented at least partially. White indicates initiative was not implemented. NA indicates that the initiative could not be reviewed from publicly available data. Each line represents one year that the conference was held, in chronological order. Conferences and years reviewed were the biannual International Congress for Conservation Biology (ICCB, 2015-2019), International Marine Conservation Congress (IMCC, 2014-2018), European Ecological Federation (EEF) Conference (2015-2019) and Society for Ecological Restoration (SER) World Conference on Ecological Restoration (2015-2019), annual conferences of the Ecological Society of America (ESA, 2017-2019), Ecological Society of Australia (ESAus, 2017-2019), British Ecological Society (BES, 2017-2019) and Association for Tropical Biology and Conservation (ATBC, 2017-2019), the conference of the International Association for Ecology (INTECOL, 2009-2017), and the IUCN World Conservation Congress (WCC) held once every 4 years (2012-2020). 


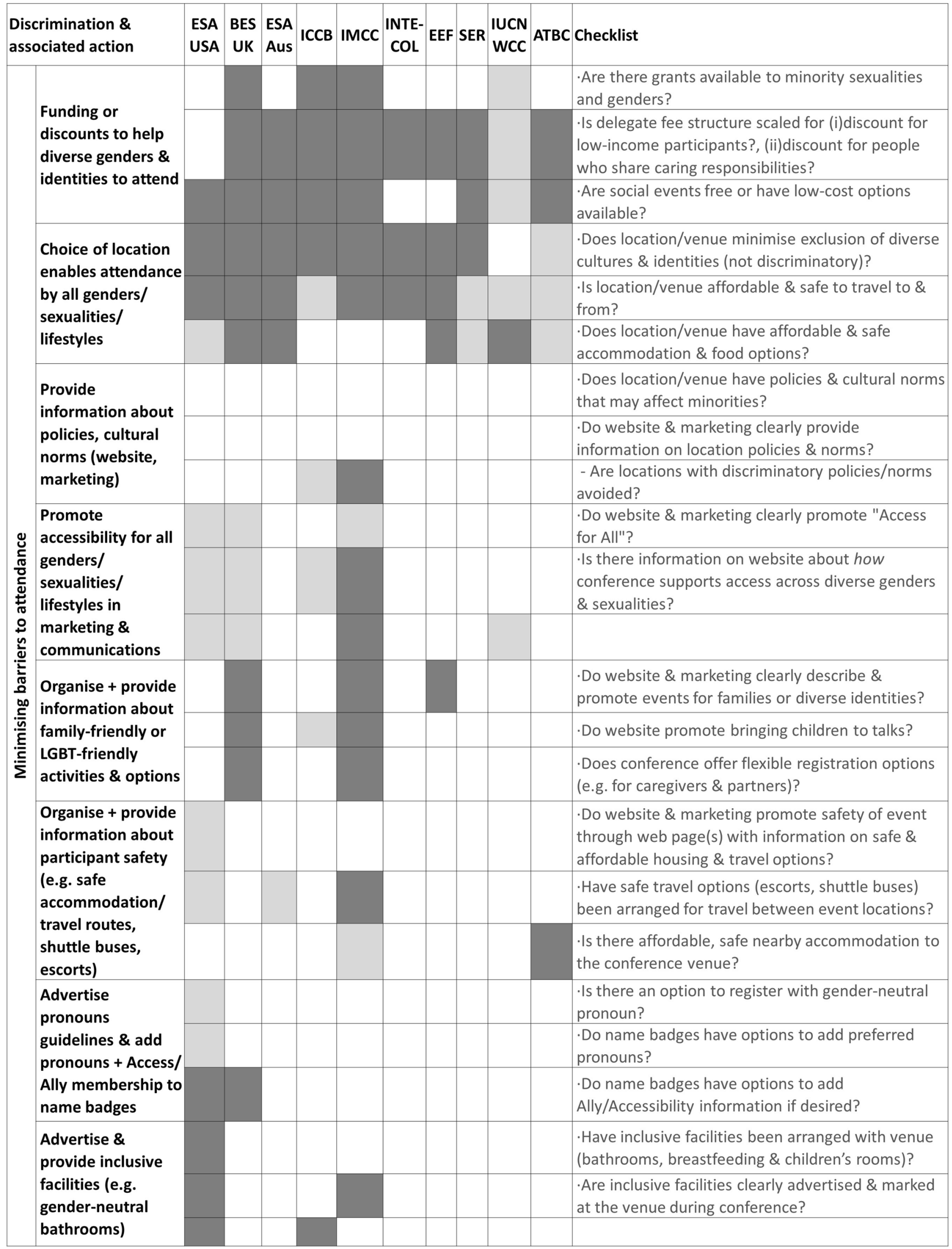

Extended Data Fig. 4 | See next page for caption. 
Extended Data Fig. 4 | Supplementary table of supporting information for Table 1, showing initiatives targeted towards "Minimising barriers to attendance". Summarizes equity, diversity and inclusion initiatives for 30 events held by 10 ecology and conservation conferences, and checklist associated with each initiative to promote its implementation. Dark grey indicates that the initiative was implemented. Light grey indicates that the initiative was not advertised but known to have been implemented at least partially. White indicates initiative was not implemented. NA indicates that the initiative could not be reviewed from publicly available data. Each line represents one year that the conference was held, in chronological order. Conferences and years reviewed were the biannual International Congress for Conservation Biology (ICCB, 2015-2019), International Marine Conservation Congress (IMCC, 2014-2018), European Ecological Federation (EEF) Conference (2015-2019) and Society for Ecological Restoration (SER) World Conference on Ecological Restoration (2015-2019), annual conferences of the Ecological Society of America (ESA, 2017-2019), Ecological Society of Australia (ESAus, 2017-2019), British Ecological Society (BES, 2017-2019) and Association for Tropical Biology and Conservation (ATBC, 2017-2019), the conference of the International Association for Ecology (INTECOL, 2009-2017), and the IUCN World Conservation Congress (WCC) held once every 4 years (2012-2020). 


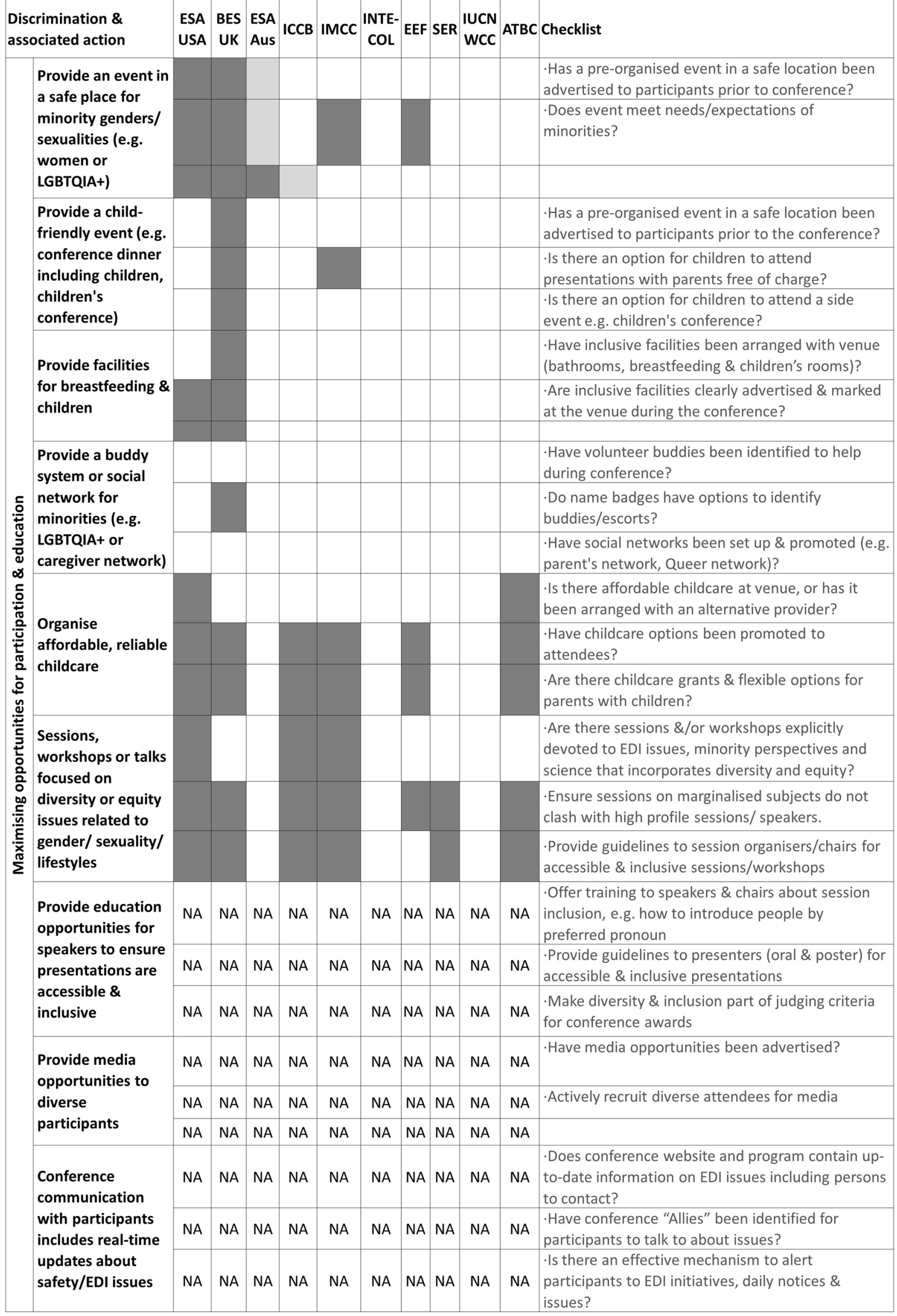

Extended Data Fig. 5 | See next page for caption. 
Extended Data Fig. 5 | Supplementary table of supporting information for Table 1, showing initiatives targeted towards “Maximising opportunities for participation \& education". Summarizes equity, diversity and inclusion initiatives for 30 events held by 10 ecology and conservation conferences, and checklist associated with each initiative to promote its implementation. Dark grey indicates that the initiative was implemented. Light grey indicates that the initiative was not advertised but known to have been implemented at least partially. White indicates initiative was not implemented. NA indicates that the initiative could not be reviewed from publicly available data. Each line represents one year that the conference was held, in chronological order. Conferences and years reviewed were the biannual International Congress for Conservation Biology (ICCB, 2015-2019), International Marine Conservation Congress (IMCC, 2014-2018), European Ecological Federation (EEF) Conference (2015-2019) and Society for Ecological Restoration (SER) World Conference on Ecological Restoration (2015-2019), annual conferences of the Ecological Society of America (ESA, 2017-2019), Ecological Society of Australia (ESAus, 2017-2019), British Ecological Society (BES, 2017-2019) and Association for Tropical Biology and Conservation (ATBC, 2017-2019), the conference of the International Association for Ecology (INTECOL, 2009-2017), and the IUCN World Conservation Congress (WCC) held once every 4 years (2012-2020). 


\begin{tabular}{|c|c|c|c|c|c|c|c|c|c|c|c|c|}
\hline \multicolumn{2}{|c|}{$\begin{array}{l}\text { Discrimination \& } \\
\text { associated action }\end{array}$} & \multirow{2}{*}{$\begin{array}{l}\text { ESA } \\
\text { USA } \\
\text { NA }\end{array}$} & \multirow{2}{*}{$\begin{array}{l}\text { BES } \\
\text { UK } \\
\text { NA }\end{array}$} & \multirow{2}{*}{$\begin{array}{l}\text { ESA } \\
\text { Aus } \\
\text { NA }\end{array}$} & \multirow{2}{*}{$\begin{array}{l}\text { ICCB } \\
\text { NA }\end{array}$} & \multirow{2}{*}{\begin{tabular}{l|} 
IMCC \\
NA
\end{tabular}} & \multirow{2}{*}{$\begin{array}{c}\text { INTE- } \\
\text { COL } \\
\text { NA }\end{array}$} & \multirow{2}{*}{\begin{tabular}{|l|l} 
EEF & \\
NA & 1
\end{tabular}} & \multirow{2}{*}{\begin{tabular}{l|l} 
SER \\
NA
\end{tabular}} & \multirow{2}{*}{$\begin{array}{l}\text { IUCN } \\
\text { WCC } \\
\text { NA }\end{array}$} & \multirow{2}{*}{$\begin{array}{l}\text { ATBC } \\
\text { NA }\end{array}$} & \multirow{2}{*}{$\begin{array}{l}\text { Checklist } \\
\text { Is there a conference assessment \& } \\
\text { reporting team? }\end{array}$} \\
\hline \multirow{6}{*}{ 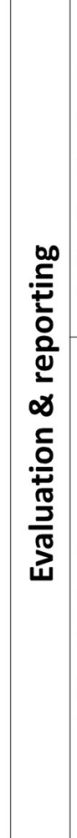 } & $\begin{array}{l}\text { Post-conference } \\
\text { evaluation of }\end{array}$ & & & & & & & & & & & \\
\hline & $\begin{array}{l}\text { diversity \& } \\
\text { equity in } \\
\text { attendance \& }\end{array}$ & NA & NA & NA & NA & NA & NA & NA & NA & NA & NA & $\begin{array}{l}\text { - Have participant surveys on } \\
\text { perceptions/experiences been constructed } \\
\text { \& delivered? }\end{array}$ \\
\hline & initiatives & NA & NA & NA & NA & NA & NA & NA & NA & NA & NA & -Have registration statistics been analysed? \\
\hline & \multirow{3}{*}{$\begin{array}{l}\text { Post-conference } \\
\text { reporting on } \\
\text { diversity \& } \\
\text { equity in } \\
\text { attendance \& } \\
\text { success of } \\
\text { initiatives }\end{array}$} & NA & NA & NA & NA & NA & NA & NA & NA & NA & NA & $\begin{array}{l}\text { Have results of conference EDI initiatives } \\
\text { been reported internally (i.e. to society } \\
\text { board, members and future conference } \\
\text { committee)? }\end{array}$ \\
\hline & & NA & NA & NA & NA & NA & NA & NA & NA & NA & NA & $\begin{array}{l}\text {-Have results of conference EDI initiatives } \\
\text { been reported externally, including } \\
\text { published on website and communicated } \\
\text { to conference venue and organisers? }\end{array}$ \\
\hline & & NA & NA & NA & NA & NA & NA & NA & NA & NA & NA & $\begin{array}{l}\text { ·Have conference EDI policies \& initiatives } \\
\text { been updated based on learnings from } \\
\text { other conferences? }\end{array}$ \\
\hline
\end{tabular}

Extended Data Fig. 6 | Supplementary table of supporting information for Table 1, showing initiatives targeted towards "Evaluation and reporting". Summarizes equity, diversity and inclusion initiatives for 30 events held by 10 ecology and conservation conferences, and checklist associated with each initiative to promote its implementation. Dark grey indicates that the initiative was implemented. Light grey indicates that the initiative was not advertised but known to have been implemented at least partially. White indicates initiative was not implemented. NA indicates that the initiative could not be reviewed from publicly available data. Each line represents one year that the conference was held, in chronological order. Conferences and years reviewed were the biannual International Congress for Conservation Biology (ICCB, 2015-2019), International Marine Conservation Congress (IMCC, 2014-2018), European Ecological Federation (EEF) Conference (2015-2019) and Society for Ecological Restoration (SER) World Conference on Ecological Restoration (2015-2019), annual conferences of the Ecological Society of America (ESA, 2017-2019), Ecological Society of Australia (ESAus, 2017-2019), British Ecological Society (BES, 2017-2019) and Association for Tropical Biology and Conservation (ATBC, 2017-2019), the conference of the International Association for Ecology (INTECOL, 2009-2017), and the IUCN World Conservation Congress (WCC) held once every 4 years (2012-2020). 